OPEN ACCESS

Edited by:

Cristina Mazzoni,

Sapienza Università

di Roma, Italy

Reviewed by:

Marco Vanoni,

Università degli studi

di Milano Bicocca, Italy

Raquel Aloyz,

Lady Davis Institute (LDI).

Canada

${ }^{*}$ Correspondence:

Cesare Indiveri

cesare.indiveri@unical.it

Specialty section:

This article was submitted to Molecular and Cellular Oncology,

a section of the journal

Frontiers in Oncology

Received: 18 October 2017 Accepted: 28 November 2017

Published: 11 December 2017

Citation:

Scalise M, Pochini L, Galluccio M, Console $L$ and Indiveri $C$ (2017)

Glutamine Transport and

Mitochondrial Metabolism in Cancer Cell Growth.

Front. Oncol. 7:306.

doi: 10.3389/fonc.2017.00306

\section{Glutamine Transport and Mitochondrial Metabolism in Cancer Cell Growth}

\author{
Mariafrancesca Scalise ${ }^{1}$, Lorena Pochini ${ }^{1}$, Michele Galluccio ${ }^{1}$, Lara Console ${ }^{1}$ \\ and Cesare Indiveri ${ }^{1,2 *}$
}

'Department DiBEST (Biologia, Ecologia, Scienze della Terra), Unit of Biochemistry and Molecular Biotechnology, University of Calabria, Arcavacata di Rende, Italy, ${ }^{2} \mathrm{CNR}$ Institute of Biomembranes, Bioenergetics and Molecular Biotechnology, Bari, Italy

The concept that cancer is a metabolic disease is now well acknowledged: many cancer cell types rely mostly on glucose and some amino acids, especially glutamine for energy supply. These findings were corroborated by overexpression of plasma membrane nutrient transporters, such as the glucose transporters (GLUTs) and some amino acid transporters such as ASCT2, LAT1, and ATB ${ }^{0,+}$, which became promising targets for pharmacological intervention. On the basis of their sodium-dependent transport modes, ASCT2 and $\mathrm{ATBO}^{+}$have the capacity to sustain glutamine need of cancer cells; while LAT1, which is sodium independent will have the role of providing cancer cells with some amino acids with plausible signaling roles. According to the metabolic reprogramming of many types of cancer cells, glucose is mainly catabolized by aerobic glycolysis in tumors, while the fate of Glutamine is completed at mitochondrial level where the enzyme Glutaminase converts Glutamine to Glutamate. Glutamine rewiring in cancer cells is heterogeneous. For example, Glutamate is converted to $\alpha$-Ketoglutarate giving rise to a truncated form of Krebs cycle. This reprogrammed pathway leads to the production of ATP mainly at substrate level and regeneration of reducing equivalents needed for cells growth, redox balance, and metabolic energy. Few studies on hypothetical mitochondrial transporter for Glutamine are reported and indirect evidences suggested its presence. Pharmacological compounds able to inhibit Glutamine metabolism may represent novel drugs for cancer treatments. Interestingly, well acknowledged targets for drugs are the Glutamine transporters of plasma membrane and the key enzyme Glutaminase.

Keywords: tumors, mitochondria, metabolism, proteoliposome, plasma membrane, drug design

\section{INTRODUCTION}

A conspicuous number of scientific reports clearly show that cancer is a metabolic disease (1-3). Metabolic reprogramming is driven by changes in expression of specific genes that allow cancer cells escaping control mechanisms active in healthy cells. The knowledge of these variations is relevant for designing novel and more specific pharmacological strategies. Therefore, many unknown or controversial aspects of cancer cell metabolism are object of active investigation. 
In this respect, mitochondria are crucial for cell survival and their features in cancer vary profoundly in terms of DNA content, electron chain functionality, and ATP production $(4,5)$. In this complex scenario, Glutamine is a key player since it is a versatile amino acid whose carbon skeleton is employed in different cell compartments for several purposes. Noteworthy, in physiological conditions as well, Glutamine is the most abundant amino acid in plasma, reaching a concentration of $0.8 \mathrm{mM}$ and it can rise up to $40 \%$ of the total amino acids intracellular content (6). Glutamine is endogenously synthesized from $\alpha$-Ketoglutarate, via Glutamate dehydrogenase and Glutamine synthetase. However, when cells are highly proliferative, the request of Glutamine increases and it has to be absorbed from external sources (7), making Glutamine a "conditionally essential" nutrient. Hence, some cancer cells are considered "glutamine addicted" because their growth and proliferation rates depended on availability of this amino acid $(8,9)$. Glutamine is engaged in different pathways, both cytosolic and mitochondrial, responsible for synthesis of many molecules (Figure 1A). Glutamine is also involved in other cell processes such as, Glutamine/Glutamate cycle in nervous tissue (Figure 1A) (10, 11). Glutamine ends its fate in mitochondria to be oxidized, producing ATP. Some aspects of the Glutamine transport and mitochondrial metabolism, which characterize cancer cells, will be dealt with. Noteworthy, Glutamine has been proposed to activate cell growth also independently from energy metabolism, by acting on signaling processes $(11,12)$.

\section{GLUTAMINE SUPPLY TO CANCER CELLS}

The higher demand of glutamine by some cancer cells requires the action of membrane transporters with two essential features: (i) specificity for Glutamine and (ii) high transport capacity. Membrane transporters for amino acids are characterized by a broad specificity. In other words, the same transporter is able to recognize different amino acids with a redundancy that is typical of this class of proteins (13). In particular, Glutamine is recognized as substrate by some of the members of four different SLC families, which are clustered on the basis of phylogenetic analyses: SLC1, SLC6, SLC7, and SLC38 (14). Each transporter can be indicated by either the SLC or the old nomenclature (Figure 1). Even though the genetic and biochemical characterization of Glutamine transporters began several years ago, many unclear aspects are still existing especially in the frame of concerted action and regulation of the transporters and to their importance in Glutamine homeostasis under physiological (Figure 1A) and pathological conditions $(13,14)$. A remark is, however, very clear: some of the transporters sharing specificity for Glutamine are overexpressed in many tumors, i.e., ASCT2, $\mathrm{ATB}^{0+}$, and LAT1 (Table 1) (15-17); notwithstanding, not all of them are suitable for providing cells with high amount of this amino acid since they do not fulfill both the features above mentioned. A concise summary of the major players of Glutamine homeostasis is reported below together with an update on the most likely transport mechanisms underlying their role in cancer.

SLC1A5 is referred to as ASCT2, acronym standing for Alanine, Serine, Cysteine Transporter according to preliminary observations on substrate specificity (13). Recently, we showed that the actual preferred substrate is Glutamine and that Cysteine is not a substrate but, probably, a modulator of transport activity, in agreement with the previous reports describing a very low transport of Cysteine, if any $(49,50)$. The specificity of ASCT2 toward Glutamine correlates well with its overexpression in several human cancers $(16,51)$; to better explain its role in Glutamine addiction, many authors depicted ASCT2 as a $\mathrm{Na}^{+}-$ dependent symporter of Glutamine, thus apparently fulfilling the two constraints above listed, i.e., specificity and high transport capacity (52-55). However, the proposed mechanistic model does not correlate with the actual transport mode of ASCT2 that is a $\mathrm{Na}^{+}$-dependent antiporter, according to both initial and more recent studies, including ours, which well clarify this aspect $(16,49,56,57)$ (Figure 1A). Therefore, at variance with the common view, the uptake of Glutamine, required by cancer cells, must be coupled to an opposite and quantitatively equal efflux of another neutral amino acid. Under a metabolic point of view, it is reasonable that the most probable exchanged amino acids are Asparagine, Threonine, or Serine; these, indeed, are high affinity substrates of ASCT2 (56) and the antiport with Glutamine will allow the net entry of 1-2 carbon atoms into the cell, which can be oxidized in the TCA to produce ATP (Figure 1B). This reaction is energetically favored by extracellular sodium gradient and membrane potential; the transporter is electrogenic due to net positive charge accumulation, as we recently highlighted (56). This "amino acid exchange" mechanism correlates well with the increased plasma concentration of Serine and Threonine, widely described in different cancers (58). Over the years, overexpression of ASCT2 has been associated also to another transporter of neutral amino acids, SLC7A5 referred to as LAT1 (59), as originally proposed by Fuchs and Bode (16). This protein is a $\mathrm{Na}^{+}$-independent obligatory antiporter and it has an heterodimeric structure, being associated to an ancillary protein named CD98 (SLC3A2) which, however, does not play any role in the intrinsic transport function (Figure 1A) (60). LAT1/CD98 heterodimer is broadly expressed and provides cells with essential amino acids, such as Leucine, in those body districts where these are required for cell growth. Indeed, strong genetic alterations of LAT1 in embryo are not compatible with life and very few are found in families characterized by some cases of Autism Spectrum Disorders, in which the metabolic damage is ascribed to altered supply/excessive loss of essential amino acids, in particular Histidine, to/from brain (61). LAT1 is greatly overexpressed in tumors where it has a role in signaling function (Table 1) $(16,51)$. Leucine, indeed, modulates the activity of one of the master cell growth regulators: mTOR (62). This protein kinase senses amino acid availability and it is particularly responsive to Leucine, Glutamine, and Arginine levels across lysosomes (62). In this respect, it is worth to note that LAT1, besides in plasma membranes, has also been found in lysosomes together with the "transceptor" SLC38A9 (63-65). Moreover, Leucine is a positive allosteric regulator of Glutamate dehydrogenase, which is responsible of Glutamine fate in mitochondria (17). For all the stated reasons, both LAT1 and ASCT2 can be considered eminent targets for drugs (51). However, the commonly proposed model in which Glutamine is taken up via 


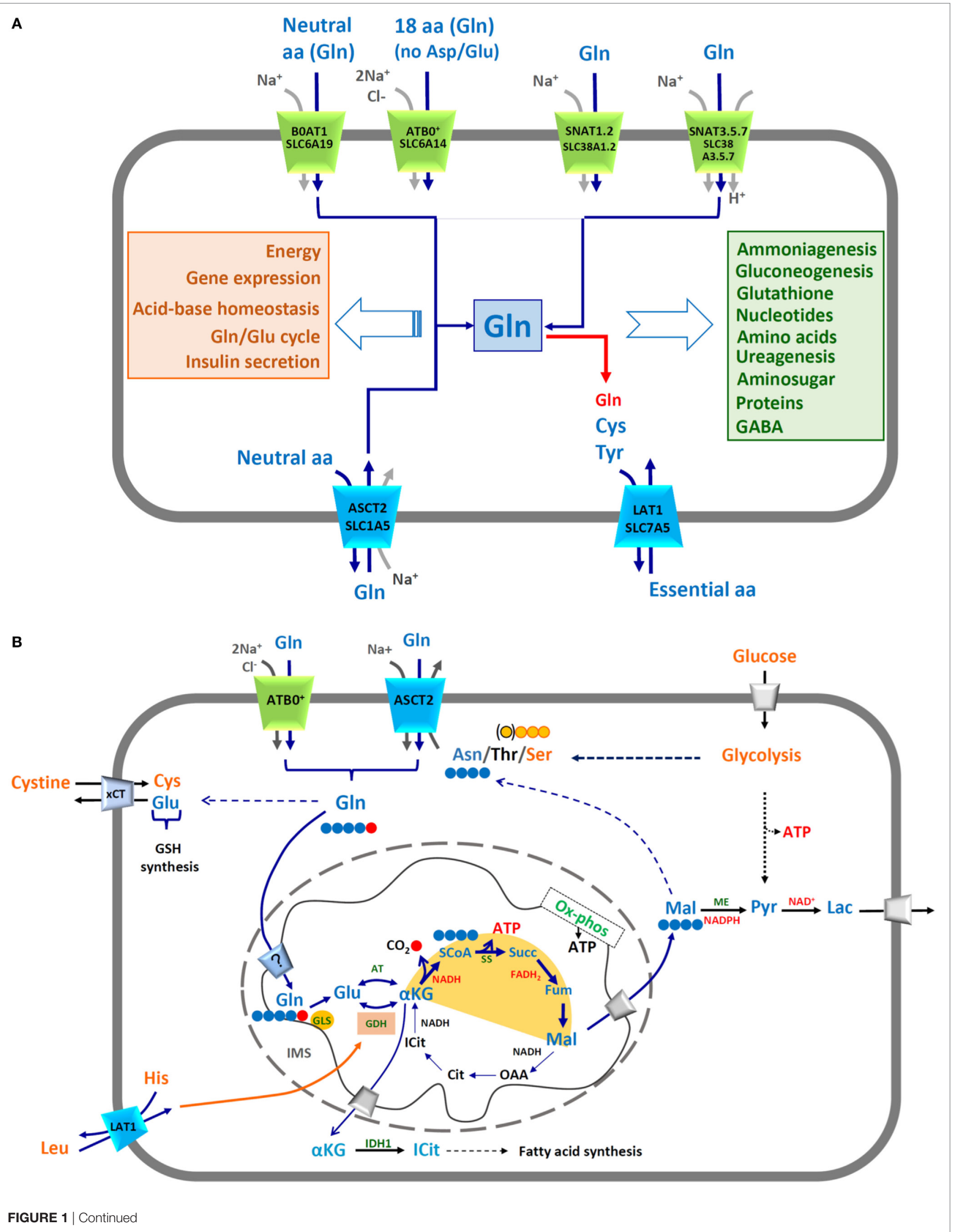


FIGURE 1 | Continued

(A) Membrane transporters of glutamine and mechanisms of transport. The shape of the transporters reflects their asymmetry in membrane. Transporters are indicated by both conventional and SLC names. Different colors highlight different transport modes: in green symporters, in blue antiporters. Arrows represent direction of transported amino acids (blue) and ion (grey) fluxes; red arrow indicates possible Glutamine exit via LAT1 (SLC7A5). In the orange box, the list of cell pathways in which Glutamine is involved; in the light green box, the list of molecules synthesized from Glutamine. (B) Mitochondrial and cytosolic pathways responsible for energy production from Glutamine. In the scheme, Glutamine (Gln, blue) uptake occurs via membrane transporters ATB ${ }^{0,+}$ and ASCT2 through a sodium coupled process. The pathways are indicated as solid or dotted (in the case of multistep pathways) arrows (in blue those related to Glutamine, in black those involved in other pathways). Carbon atoms of Gln are depicted in blue-red filled circles; Gln enters mitochondria via an inner membrane transporter whose existence is still questionable (?): it could be a Glutamine or a Glutamate transporter depending on the actual sub-localization of Glutaminase enzyme (GLS). Carbon atom derived from Gln and released as $\mathrm{CO}_{2}$ is indicated in red, carbon skeleton of Malate and Asparagine (Asn) in blue, carbon skeletons of Serine (Ser) in orange circled in red and of Threonine (Thr) in orange circled in black. The truncated form of TCA is highlighted by a yellow hemicycle. ATP and reducing equivalent molecules produced by Glutamine metabolism are indicated in red. Leucine enters through LAT1 and allosterically regulates GDH in the orange box. Some metabolic pathways are indicated by names: GSH synthesis, fatty acid synthesis, Glycolysis, OX-phos. Membrane transporters of lactate and glucose in grey, xCT in light blue. Enzymes highlighted: GLS, Glutaminase; GDH, Glutamate dehydrogenase; AT, aminotransferases; SS, succinylCoA synthetase; ME, malic enzyme; IDH1, isocitrate dehydrogenase. Amino acids and other molecules involved in glutamine pathways (azure): Glu, Glutamate; $\alpha$-KG, $\alpha$-ketoglutarate; ICit, isocitrate; SCoA, succinyl coenzyme A; Succ, succinate; Fum, fumarate; Mal, malate; OAA, oxaloacetate; Cit, citrate; Pyr, pyruvate; Lac, lactate.

TABLE $1 \mid$ ATB $^{0,+}$, ASCT2, and LAT1-associated cancers.

\begin{tabular}{|c|c|c|c|}
\hline SLC6A14 $\left(\right.$ ATB $\left.^{0,+}\right)$ & SLC1A5 (ASCT2) & SLC7A5 (LAT1) & Reference \\
\hline Prostate cancer & Prostate cancer & Prostate cancer & $(14,18-22)$ \\
\hline Colorectal cancer & $\begin{array}{l}\text { Colorectal cancer } \\
\text { Hepato cell carcinoma } \\
\text { Lung cancer }\end{array}$ & $\begin{array}{l}\text { Colorectal cancer } \\
\text { Hepato cell carcinoma } \\
\text { Lung cancer }\end{array}$ & $\begin{array}{c}(14,23) \\
(14) \\
(14,24)\end{array}$ \\
\hline Breast cancer & $\begin{array}{l}\text { Breast cancer } \\
\text { Neuroblastoma and glioma } \\
\text { Endometrioid carcinoma } \\
\text { Ovarian cancer } \\
\text { Renal cell carcinoma }\end{array}$ & $\begin{array}{l}\text { Breast cancer } \\
\text { Neuroblastoma and glioma } \\
\text { Endometrioid carcinoma } \\
\text { Ovarian cancer } \\
\text { Renal cell carcinoma }\end{array}$ & $\begin{array}{c}(14,18,25-28) \\
(14,29) \\
(14,30,31) \\
(14,32) \\
(14,33,34)\end{array}$ \\
\hline Pancreatic and biliary tract cancer & Gastric cancer & $\begin{array}{l}\text { Pancreatic and biliary tract cancer } \\
\text { Gastric cancer } \\
\text { Pleural mesothelioma }\end{array}$ & $\begin{array}{c}(14,35,36) \\
(14,37-40) \\
(14)\end{array}$ \\
\hline Cervical cancer & $\begin{array}{l}\text { Cervical cancer } \\
\text { Oral squamous cell carcinoma }\end{array}$ & $\begin{array}{l}\text { Oral squamous cell carcinoma } \\
\text { Thymic cancer } \\
\text { Melanoma } \\
\text { Leukemia }\end{array}$ & $\begin{array}{c}(41,42) \\
(43-45) \\
(46) \\
(47) \\
(48)\end{array}$ \\
\hline
\end{tabular}

List of cancer tissues in which ATB ${ }^{0,+}$, ASCT2, and/or LAT1 have been found overexpressed with related references.

ASCT2 to boost the transport cycle of LAT1, for massive entry of Leucine, is questionable. Indeed, as above described, ASCT2 is not a symporter, but an antiporter, and Glutamine is a poor substrate of LAT1 (60) (Figure 1). Thus, it is necessary to reconsider an integrated view of metabolism, which takes into account other membrane transporters. In particular, two members of SLC6 family are characterized by both specificity for Glutamine and high transport capacity and are involved in supplying it to cells in physiological and pathological conditions (Figure 1): SLC6A14 and SLC6A19 known as $\mathrm{ATB}^{0,+}$ and $\mathrm{B}^{0} \mathrm{AT} 1$, respectively (66). In the case of $\mathrm{ATB}^{0,+}$, Glutamine uptake has been proposed to be coupled with $2 \mathrm{Na}^{+}$and $1 \mathrm{Cl}^{-}$while, in the case of $\mathrm{B}^{0} \mathrm{AT} 1$, it is coupled to $\mathrm{Na}^{+}$(Figure 1A). The transport cycle of the two proteins is electrogenic making $\mathrm{ATB}^{0,+}$ and $\mathrm{B}^{0} \mathrm{AT} 1$ high capacity transporters. Despite this, no involvement in cancer is reported for $\mathrm{B}^{0} \mathrm{AT} 1$, so far. Altered expression of this protein is described only in an inherited disease referred to as Hartnup disorder (67). On the contrary, a number of studies shows overexpression of $\mathrm{ATB}^{0,+}$ in human cancers $(25,51)$ (Table 1). Therefore, this protein can be considered one of the players in accomplishing metabolic needs of cancer cells and, hence, a druggable target (Figure 1B). However, at this stage, a plausible unified model, including ASCT2, LAT1, and $\mathrm{ATB}^{0,+}$ cannot be predicted because the study on biology of the last one is still in embryonic form. The only available information concerns its broad specificity and localization (66). Another family characterized by a sizable number of Glutamine transporters is the SLC38, which accounts for 11 members, the best known of which are described as Glutamine transporters coupled to $\mathrm{Na}^{+}$or $\mathrm{Na}^{+} / \mathrm{H}^{+}$fluxes (68) (Figure 1A). Wide proteomic/genomic data indicate that some of the SLC38 members are overexpressed in human cancers (69). Further studies are required to establish a direct role of these transporters in Glutamine supply and, hence, their possible consideration as drug targets. Noteworthy, an important advancement has been recently provided in the field of cell signaling linked to amino acid sensing with the discovery that SLC38A9 is a lysosomal transporter responsible for Glutamine and Arginine flux across lysosome with consequent activation of mTOR cascade $(64,65)$. 


\section{GLUTAMINE METABOLISM IN MITOCHONDRIA AND THE STILL UNSOLVED TRANSPORT ISSUE}

The relevance of Glutamine for energy production underlies a truncated form of TCA characterizing the mitochondrial metabolism of several type of cancers. In this pathway, the cycle is not completed and the carbon skeleton of Glutamine, entering the TCA as $\alpha$-Ketoglutarate, escapes as Malate with production of ATP at substrate level in the reaction catalyzed by the SuccinylCoA Synthetase. According to this pathway, one out of the five carbon atoms of Glutamine, is released as $\mathrm{CO}_{2}$ (Figure 1B). The four remaining carbon atoms of Glutamine are exported in cytosol as Malate that can give rise to different metabolic pathways. It can be converted into Pyruvate leading to NADPH production that can be used by fatty acid synthesis or other biosynthetic pathways (70). Pyruvate can, in turn, be transformed to Lactate, restoring $\mathrm{NAD}^{+}$needed for anaerobic glycolysis and production of ATP (Figure 1B). This typical anaerobic pathway occurs even in the presence of adequate oxygen supply, according to the wellacknowledged Warburg hypothesis (16, 71, 72). Alternatively, Malate can enter four carbon atom molecules among which Asparagine, i.e., one of the substrates necessary for ASCT2 transport cycle (Figure 1B). In this case, Malate is converted into oxaloacetate via malate dehydrogenase and then, to aspartate via aspartate aminotransferase (resumed by the dotted arrow of Figure 1B). The alternative efflux substrate of ASCT2, Serine can derive from glucose via a three enzymes pathway, i.e., phosphoglycerate dehydrogenase, phosphoserine aminotransferase, and phosphoserine phosphatase (resumed by the dotted arrow of Figure 1B). Noteworthy, the reaction catalyzed by the second enzyme (aminotransferase) requires Glutamate, which in turn derives from Glutamine. On the other hand, Threonine, which could be an efflux substrate of ASCT2 as well, is an essential amino acid; thus, it should derive from import through other transporters or, hypothetically, from protein degradation. Moreover, Glutamine skeleton can also fuel fatty acid synthesis in cytosol by reductive carboxylation of $\alpha$-Ketoglutarate, exported from mitochondria, to isocitrate through the action of a cytosolic isoform of IDH (Figure 1B). This is a non-conventional reaction for producing citrate, occurring in cells that undergo metabolic switch $(70,73,74)$. Glutamine is involved also in ROS metabolism, which is another crucial point for cancer development and progression (75). Cancer cells, indeed, need to keep the production of ROS under strict control via mechanisms involving both enhanced glutathione (Glutamate-Glycine-Cysteine-GSH) synthesis and decreased respiratory chain activity. Glutamate needed for GSH synthesis derives, under these conditions, from Glutamine (Figure 1B) (76). Cysteine is taken up by cells via the Glutamate/Cystine transporter xCT (SLC7A11), which has been found overexpressed in several cancers and is responsible for a novel way of cell death called ferroptosis (77). Thus, Glutamine withdrawal can have dramatic effects on cancer cell metabolism $(75,78)$. Despite the described importance of Glutamine in mitochondrial metabolism, the network of proteins involved in its flux to mitochondrial matrix is still underneath. Several efforts have been made to shed light on two mitochondrial molecular entities, which are still mysterious: the enzyme Glutaminase and the mitochondrial transporter for Glutamine (Figure 1B). Glutaminase is produced by two different genes: GLS1 and GLS2. The first one is known as kidney-type Glutaminase and is ubiquitously expressed. The GLS2 gene is known as liver-type glutaminase (LGA) and is mainly expressed in liver. The GLS1 type is subjected to alternative splicing producing a full isoform and a truncated one, which differs for its C-ter region and is known as Glutaminase C (79). These two isoforms have been found overexpressed in different cancers, in line with the increased metabolic demand of mitochondrial Glutamine (80). The importance of this enzyme in the fate of Glutamine is testified by a number of different pathways involved in its regulation among which, c-Myc, whose action is exerted through inhibition of a microRNA, miRNA-23a that results in increased GLS1 expression and, then, activity (81). Under a pharmacological point of view, Glutaminase represents an important target for anticancer therapy (82). However, the sub-localization of mitochondrial Glutaminase is not yet defined and, as a consequence, the need of a mitochondrial Glutamine transporter. In fact, if Glutaminase faces the intermembrane space, here, releases Glutamate then, a Glutamate transporter, not a Glutamine one, is required to allow entry of Glutamate in the TCA. On the contrary, if Glutaminase faces the intra-mitochondrial matrix, then a Glutamine transporter is necessary to allow Glutamine reaching the substrate active site of Glutaminase (Figure 1B). Biochemical data, even though indirect, agree with the second hypothesis and, hence, with the existence of a Glutamine transporter (Figure 1B) whose molecular identity is not yet revealed (82-86). We have conducted in silico analyses aligning a putative Glutamine binding motif with members of the mitochondrial transporter SLC25 family: the best score was obtained for three orphan SLC25 members resulting as possible mitochondrial Glutamine transporters (11).

\section{GLUTAMINE METABOLISM AS TARGET FOR DRUGS}

The complex network of enzymes/transporters involved in Glutamine metabolism explains the plethora of drug interventions to specifically target cancer cells. A big challenge is the metabolic adaptation of cancer cells that can survive also under stress conditions, such as Glutamine withdrawal $(87,88)$. Last, but not less important, is the great diversity of cancers; thus, it is not surprising that therapeutic interventions needs to be specifically designed. Being Glutamine a key player in multiple pathways, the most important makers of its fate represent potential crossroad for cancer therapy. In particular, inhibitors of the key enzyme Glutaminase have been designed over the years $(7,82)$ and their studies are at a more advanced stage, being Glutaminase a soluble protein, i.e., easier to handle also in vitro. Interestingly, murine Glutaminase 3D structure has been obtained (pdb 4JKT) and, very recently, the human one has been deposited in the database (pdb 5UQE), as well. Some inhibitors showed very good results in in vitro models of human cancers and few of them were promising in preclinical studies. In particular, one synthetic compound, i.e., CD-839 reached clinical trials due to its ability to block tumor growth in vitro, in vivo, and in mouse models 
(89). The main challenges with respect to Glutaminase inhibitors are the presence of more than one isoform of GLS and the still unsolved issue of subcellular localization that can hamper the drug availability. The scenario around membrane transporters is even more complex. In fact, their relevance in pharmacology is obvious and relies on two main aspects: membrane proteins can be (i) target of designed drugs and/or (ii) responsible for drug traffic across membranes and, thus, for drug disposition. This second aspect is still not fully considered by the scientific community that did not include any transporter for amino acids in the list of the International Transporter Consortium for drug-transporter interactions (90). The frontiers of drug design are based on in silico models that, on the one hand, reduce the number of experimental analysis to be conducted; on the other hand, if the $3 \mathrm{D}$ model of the protein is obtained by homology, predictions may be uncertain. This circumstance, in the case of membrane transporter, occurs quite often because few 3D structures are available so far. The well-documented overexpression of some membrane transporters, above described (see Glutamine Supply to Cancer Cells; Table 1), boosted the research of potent and specific inhibitors; in particular, several reports dealt with the identification of inhibitors for ASCT2 (91) and LAT1 (92) via bioinformatics. The initial approach, attempted over the years, has been that of designing substrate analogs-based drugs to block either ASCT2 or LAT1 transport activities $(93,94)$. However, all the discovered molecules exhibited relatively low affinities and, hence, low effects on reducing cancer cell viability. The pitfalls of this strategy are explained by the frame schematically depicted in Figure 1A; in fact, membrane transporters of amino acids are poly-specific meaning that natural substrates can displace a hypothetical substrate-based drug. These compounds, in fact, interact

\section{REFERENCES}

1. Robey RB, Weisz J, Kuemmerle NB, Salzberg AC, Berg A, Brown DG, et al. Metabolic reprogramming and dysregulated metabolism: cause, consequence and/or enabler of environmental carcinogenesis? Carcinogenesis (2015) 36(Suppl 1):S203-31. doi:10.1093/carcin/bgv037

2. Icard P, Lincet H. A global view of the biochemical pathways involved in the regulation of the metabolism of cancer cells. Biochim Biophys Acta (2012) 1826(2):423-33. doi:10.1016/j.bbcan.2012.07.001

3. Hanahan D, Weinberg RA. Hallmarks of cancer: the next generation. Cell (2011) 144(5):646-74. doi:10.1016/j.cell.2011.02.013

4. Wisnovsky S, Lei EK, Jean SR, Kelley SO. Mitochondrial chemical biology: new probes elucidate the secrets of the powerhouse of the cell. Cell Chem Biol (2016) 23(8):917-27. doi:10.1016/j.chembiol.2016.06.012

5. Lleonart ME, Grodzicki R, Graifer DM, Lyakhovich A. Mitochondrial dysfunction and potential anticancer therapy. Med Res Rev (2017) 37(6):1275-98. doi:10.1002/med.21459

6. Cynober LA. Plasma amino acid levels with a note on membrane transport: characteristics, regulation, and metabolic significance. Nutrition (2002) 18(9):761-6. doi:10.1016/S0899-9007(02)00780-3

7. Altman BJ, Stine ZE, Dang CV. From Krebs to clinic: glutamine metabolism to cancer therapy. Nat Rev Cancer (2016) 16(10):619-34. doi:10.1038/nrc.2016.71

8. Zhang J, Pavlova NN, Thompson CB. Cancer cell metabolism: the essential role of the nonessential amino acid, glutamine. EMBO J (2017) 36(10):1302-15. doi:10.15252/embj.201696151

9. Tardito S, Oudin A, Ahmed SU, Fack F, Keunen O, Zheng L, et al. Glutamine synthetase activity fuels nucleotide biosynthesis and supports growth of glutamine-restricted glioblastoma. Nat Cell Biol (2015) 17(12):1556-68. doi: $10.1038 /$ ncb3272 only transiently with the target protein leading to scarce effects. In the recent years, we have exploited a combined approach of bioinformatics, in silico screening and biochemical assays using the in vitro experimental model of proteoliposomes in order to identify covalent inhibitors for both ASCT2 and LAT1. Being irreversible, covalent inhibitors should be in principle, more efficient in chemically knocking-out the transporters. This strategy has the advantage of facilitating the compound screening studying the effects on the sole target protein, without interferences deriving from other systems present in the whole cells (95). Then, we identified potent covalent inhibitors of the rat ASCT2 (96). Soon after, we obtained also a set of covalent inhibitors of human LAT1 with the highest affinity so far described (97). LAT1, as mentioned above, even if is probably not directly linked to Glutamine uptake in cancer cells, is responsible for providing essential amino acids, among which Leucine (see Glutamine Supply to Cancer Cells). Test in intact cells showed that the compounds were also able to impair viability of cancer cells.

\section{AUTHOR CONTRIBUTIONS}

MS and CI wrote the manuscript and designed the figures. MG, LP, and LC contributed to revision of the manuscript, figures, and bibliography.

\section{FUNDING}

This work was supported by funds from: Programma Operativo Nazionale [01_00937]_MIUR "Modelli sperimentali biotecnologici integrati per lo sviluppo e la selezione di molecole di interesse per la salute dell'uomo" to CI.

10. Curi R, Lagranha CJ, Doi SQ, Sellitti DF, Procopio J, Pithon-Curi TC, et al. Molecular mechanisms of glutamine action. J Cell Physiol (2005) 204(2): 392-401. doi:10.1002/jcp.20339

11. Scalise M, Pochini L, Galluccio M, Indiveri C. Glutamine transport. From energy supply to sensing and beyond. Biochim Biophys Acta (2016) 1857(8): 1147-57. doi:10.1016/j.bbabio.2016.03.006

12. Cacace A, Sboarina M, Vazeille T, Sonveaux P. Glutamine activates STAT3 to control cancer cell proliferation independently of glutamine metabolism. Oncogene (2017) 36(15):2074-84. doi:10.1038/onc.2016.364

13. Bode BP. Recent molecular advances in mammalian glutamine transport. J Nutr (2001) 131(9 Suppl):2475S-85S.

14. Pochini L, Scalise M, Galluccio M, Indiveri C. Membrane transporters for the special amino acid glutamine: structure/function relationships and relevance to human health. Front Chem (2014) 2:61. doi:10.3389/fchem. 2014.00061

15. Bhutia YD, Ganapathy V. Glutamine transporters in mammalian cells and their functions in physiology and cancer. Biochim Biophys Acta (2016) 1863(10):2531-9. doi:10.1016/j.bbamcr.2015.12.017

16. Fuchs BC, Bode BP. Amino acid transporters ASCT2 and LAT1 in cancer: partners in crime? Semin Cancer Biol (2005) 15(4):254-66. doi:10.1016/ j.semcancer.2005.04.005

17. Broer S, Broer A. Amino acid homeostasis and signalling in mammalian cells and organisms. Biochem J (2017) 474(12):1935-63. doi:10.1042/BCJ20 160822

18. Chiotellis A, Muller A, Weyermann K, Leutwiler DS, Schibli R, Ametamey SM, et al. Synthesis and preliminary biological evaluation of O-2((2-[(18)F]fluoroethyl)methylamino)ethyltyrosine $([(18) \mathrm{F}]$ FEMAET) as a potential cationic amino acid PET tracer for tumor imaging. Amino Acids (2014) 46(8):1947-59. doi:10.1007/s00726-014-1754-7 
19. Wang Q, Hardie RA, Hoy AJ, van Geldermalsen M, Gao D, Fazli L, et al. Targeting ASCT2-mediated glutamine uptake blocks prostate cancer growth and tumour development. J Pathol (2015) 236(3):278-89. doi:10.1002/ path. 4518

20. Xu M, Sakamoto S, Matsushima J, Kimura T, Ueda T, Mizokami A, et al. Up-regulation of LAT1 during antiandrogen therapy contributes to progression in prostate cancer cells. J Urol (2016) 195(5):1588-97. doi:10.1016/j. juro.2015.11.071

21. Yanagisawa N, Satoh T, Hana K, Ichinoe M, Nakada N, Endou H, et al. L-amino acid transporter 1 may be a prognostic marker for local progression of prostatic cancer under expectant management. Cancer Biomark (2015) 15(4):365-74. doi:10.3233/CBM-150486

22. Wang Q, Bailey CG, Ng C, Tiffen J, Thoeng A, Minhas V, et al. Androgen receptor and nutrient signaling pathways coordinate the demand for increased amino acid transport during prostate cancer progression. Cancer Res (2011) 71(24):7525-36. doi:10.1158/0008-5472.CAN-11-1821

23. Gupta N, Miyauchi S, Martindale RG, Herdman AV, Podolsky R, Miyake K, et al. Upregulation of the amino acid transporter ATB0,+ (SLC6A14) in colorectal cancer and metastasis in humans. Biochim Biophys Acta (2005) 1741(1-2):215-23. doi:10.1016/j.bbadis.2005.04.002

24. Hassanein M, Qian J, Hoeksema MD, Wang J, Jacobovitz M, Ji X, et al. Targeting SLC1a5-mediated glutamine dependence in non-small cell lung cancer. Int J Cancer (2015) 137(7):1587-97. doi:10.1002/ijc.29535

25. Babu E, Bhutia YD, Ramachandran S, Gnanaprakasam JP, Prasad PD, Thangaraju M, et al. Deletion of the amino acid transporter Slc6a14 suppresses tumour growth in spontaneous mouse models of breast cancer. Biochem $J$ (2015) 469(1):17-23. doi:10.1042/BJ20150437

26. McCracken AN, Edinger AL. Targeting cancer metabolism at the plasma membrane by limiting amino acid access through SLC6A14. Biochem J (2015) 470(3):e17-9. doi:10.1042/BJ20150721

27. van Geldermalsen M, Wang Q, Nagarajah R, Marshall AD, Thoeng A, Gao D, et al. ASCT2/SLC1A5 controls glutamine uptake and tumour growth in triple-negative basal-like breast cancer. Oncogene (2016) 35(24):3201-8. doi:10.1038/onc.2015.381

28. Li L, Di X, Wu M, Sun Z, Zhong L, Wang Y, et al. Targeting tumor highlyexpressed LAT1 transporter with amino acid-modified nanoparticles: toward a novel active targeting strategy in breast cancer therapy. Nanomedicine (2017) 13(3):987-98. doi:10.1016/j.nano.2016.11.012

29. Li L, Di X, Zhang S, Kan Q, Liu H, Lu T, et al. Large amino acid transporter 1 mediated glutamate modified docetaxel-loaded liposomes for glioma targeting. Colloids Surf B Biointerfaces (2016) 141:260-7. doi:10.1016/j. colsurfb.2016.01.041

30. Marshall AD, van Geldermalsen M, Otte NJ, Lum T, Vellozzi M, Thoeng A, et al. ASCT2 regulates glutamine uptake and cell growth in endometrial carcinoma. Oncogenesis (2017) 6(7):e367. doi:10.1038/oncsis.2017.70

31. Marshall AD, van Geldermalsen M, Otte NJ, Anderson LA, Lum T, Vellozzi MA, et al. LAT1 is a putative therapeutic target in endometrioid endometrial carcinoma. Int J Cancer (2016) 139(11):2529-39. doi:10.1002/ ijc. 30371

32. Bjersand K, Seidal T, Sundstrom-Poromaa I, Akerud H, Skirnisdottir I. The clinical and prognostic correlation of HRNPM and SLC1A5 in pathogenesis and prognosis in epithelial ovarian cancer. PLoS One (2017) 12(6):e0179363. doi:10.1371/journal.pone.0179363

33. Liu Y, Yang L, An H, Chang Y, Zhang W, Zhu Y, et al. High expression of Solute Carrier Family 1, member 5 (SLC1A5) is associated with poor prognosis in clear-cell renal cell carcinoma. Sci Rep (2015) 5:16954. doi:10.1038/ srep 16954

34. Liu W, Chen H, Wong N, Haynes W, Baker CM, Wang X. Pseudohypoxia induced by miR-126 deactivation promotes migration and therapeutic resistance in renal cell carcinoma. Cancer Lett (2017) 394:65-75. doi:10.1016/j. canlet.2017.02.025

35. Coothankandaswamy V, Cao S, Xu Y, Prasad PD, Singh PK, Reynolds CP, et al. Amino acid transporter SLC6A14 is a novel and effective drug target for pancreatic cancer. Br J Pharmacol (2016) 173(23):3292-306. doi:10.1111/ bph.13616

36. Penheiter AR, Erdogan S, Murphy SJ, Hart SN, Felipe Lima J, Rakhshan Rohakhtar F, et al. Transcriptomic and immunohistochemical profiling of SLC6A14 in pancreatic ductal adenocarcinoma. Biomed Res Int (2015) 2015: 593572. doi:10.1155/2015/593572
37. Lu J, Chen M, Tao Z, Gao S, Li Y, Cao Y, et al. Effects of targeting SLC1A5 on inhibiting gastric cancer growth and tumor development in vitro and in vivo. Oncotarget (2017) 8(44):76458-67. doi:10.18632/oncotarget.19479

38. Kasai N, Sasakawa A, Hosomi K, Poh TW, Chua BL, Yong WP, et al. Antitumor efficacy evaluation of a novel monoclonal antibody targeting neutral amino acid transporter ASCT2 using patient-derived xenograft mouse models of gastric cancer. Am J Transl Res (2017) 9(7):3399-410.

39. Hayashi K, Anzai N. Novel therapeutic approaches targeting L-type amino acid transporters for cancer treatment. World J Gastrointest Oncol (2017) 9(1):21-9. doi:10.4251/wjgo.v9.i1.21

40. Wang J, Fei X, Wu W, Chen X, Su L, Zhu Z, et al. SLC7A5 functions as a downstream target modulated by CRKL in metastasis process of gastric cancer SGC-7901 cells. PLoS One (2016) 11(11):e0166147. doi:10.1371/journal. pone. 0166147

41. Gupta N, Prasad PD, Ghamande S, Moore-Martin P, Herdman AV, Martindale RG, et al. Up-regulation of the amino acid transporter $\operatorname{ATB}(0,+)$ (SLC6A14) in carcinoma of the cervix. Gynecol Oncol (2006) 100(1):8-13. doi:10.1016/j.ygyno.2005.08.016

42. Broer A, Rahimi F, Broer S. Deletion of amino acid transporter ASCT2 (SLC1A5) reveals an essential role for transporters SNAT1 (SLC38A1) and SNAT2 (SLC38A2) to sustain glutaminolysis in cancer cells. J Biol Chem (2016) 291(25):13194-205. doi:10.1074/jbc.M115.700534

43. Cetindis M, Biegner T, Munz A, Teriete P, Reinert S, Grimm M. Glutaminolysis and carcinogenesis of oral squamous cell carcinoma. Eur Arch Otorhinolaryngol (2016) 273(2):495-503. doi:10.1007/s00405-015-3543-7

44. Honjo H, Kaira K, Miyazaki T, Yokobori T, Kanai Y, Nagamori S, et al. Clinicopathological significance of LAT1 and ASCT2 in patients with surgically resected esophageal squamous cell carcinoma. J Surg Oncol (2016) 113(4):381-9. doi:10.1002/jso.24160

45. Nikkuni O, Kaira K, Toyoda M, Shino M, Sakakura K, Takahashi K, et al. Expression of amino acid transporters (LAT1 and ASCT2) in patients with stage III/IV laryngeal squamous cell carcinoma. Pathol Oncol Res (2015) 21(4):1175-81. doi:10.1007/s12253-015-9954-3

46. Hayashi K, Jutabha P, Maeda S, Supak Y, Ouchi M, Endou H, et al. LAT1 acts as a crucial transporter of amino acids in human thymic carcinoma cells. J Pharmacol Sci (2016) 132(3):201-4. doi:10.1016/j.jphs.2016.07.006

47. Shimizu A, Kaira K, Kato M, Yasuda M, Takahashi A, Tominaga H, et al. Prognostic significance of L-type amino acid transporter 1 (LAT1) expression in cutaneous melanoma. Melanoma Res (2015) 25(5):399-405. doi:10.1097/ CMR.0000000000000181

48. Rosilio C, Nebout M, Imbert V, Griessinger E, Neffati Z, Benadiba J, et al. L-type amino-acid transporter 1 (LAT1): a therapeutic target supporting growth and survival of T-cell lymphoblastic lymphoma/T-cell acute lymphoblastic leukemia. Leukemia (2015) 29(6):1253-66. doi:10.1038/leu.2014.338

49. Utsunomiya-Tate N, Endou H, Kanai Y. Cloning and functional characterization of a system ASC-like Na+-dependent neutral amino acid transporter. J Biol Chem (1996) 271(25):14883-90. doi:10.1074/jbc.271.25.14883

50. Scalise M, Pochini L, Pingitore P, Hedfalk K, Indiveri C. Cysteine is not a substrate but a specific modulator of human ASCT2 (SLC1A5) transporter. FEBS Lett (2015) 589(23):3617-23. doi:10.1016/j.febslet.2015.10.011

51. Bhutia YD, Babu E, Ramachandran S, Ganapathy V. Amino Acid transporters in cancer and their relevance to "glutamine addiction": novel targets for the design of a new class of anticancer drugs. Cancer Res (2015) 75(9):1782-8. doi:10.1158/0008-5472.CAN-14-3745

52. Zhu Y, Li T, Ramos da Silva S, Lee JJ, Lu C, Eoh H, et al. A critical role of glutamine and Asparagine gamma-nitrogen in nucleotide biosynthesis in cancer cells hijacked by an oncogenic virus. MBio (2017) 8(4):e1179-1117. doi:10.1128/mBio.01179-17

53. Toda K, Nishikawa G, Iwamoto M, Itatani Y, Takahashi R, Sakai Y, et al. Clinical role of ASCT2 (SLC1A5) in KRAS-mutated colorectal cancer. Int J Mol Sci (2017) 18(8):E1632. doi:10.3390/ijms18081632

54. Ratnikov B, Jeon YJ, Smith JW, Ronai ZA. Right on TARGET: glutamine metabolism in cancer. Oncoscience (2015) 2(8):681-3. doi:10.18632/ oncoscience. 205

55. Nicklin P, Bergman P, Zhang B, Triantafellow E, Wang H, Nyfeler B, et al. Bidirectional transport of amino acids regulates mTOR and autophagy. Cell (2009) 136(3):521-34. doi:10.1016/j.cell.2008.11.044

56. Scalise M, Pochini L, Panni S, Pingitore P, Hedfalk K, Indiveri C. Transport mechanism and regulatory properties of the human amino acid transporter 
ASCT2 (SLC1A5). Amino Acids (2014) 46(11):2463-75. doi:10.1007/s00726014-1808-x

57. Pingitore P, Pochini L, Scalise M, Galluccio M, Hedfalk K, Indiveri C. Large scale production of the active human ASCT2 (SLC1A5) transporter in Pichia pastoris - functional and kinetic asymmetry revealed in proteoliposomes. Biochim Biophys Acta (2013) 1828(9):2238-46. doi:10.1016/ j.bbamem.2013.05.034

58. Bi X, Henry CJ. Plasma-free amino acid profiles are predictors of cancer and diabetes development. Nutr Diabetes (2017) 7(3):e249. doi:10.1038/ nutd. 2016.55

59. Mastroberardino L, Spindler B, Pfeiffer R, Skelly PJ, Loffing J, Shoemaker CB, et al. Amino-acid transport by heterodimers of 4F2hc/CD98 and members of a permease family. Nature (1998) 395(6699):288-91. doi:10.1038/26246

60. Napolitano L, Scalise M, Galluccio M, Pochini L, Albanese LM, Indiveri C. LAT1 is the transport competent unit of the LAT1/CD98 heterodimeric amino acid transporter. Int J Biochem Cell Biol (2015) 67:25-33. doi:10.1016/ j.biocel.2015.08.004

61. Tarlungeanu DC, Deliu E, Dotter CP, Kara M, Janiesch PC, Scalise M, et al. Impaired amino acid transport at the blood brain barrier is a cause of autism spectrum disorder. Cell (2016) 167(6):1481.e-94.e. doi:10.1016/ j.cell.2016.11.013

62. Laplante M, Sabatini DM. mTOR signaling in growth control and disease. Cell (2012) 149(2):274-93. doi:10.1016/j.cell.2012.03.017

63. Milkereit R, Persaud A, Vanoaica L, Guetg A, Verrey F, Rotin D. LAPTM4b recruits the LAT1-4F2hc Leu transporter to lysosomes and promotes mTORC1 activation. Nat Commun (2015) 6:7250. doi:10.1038/ncomms8250

64. Rebsamen M, Pochini L, Stasyk T, de Araujo ME, Galluccio M, Kandasamy RK, et al. SLC38A9 is a component of the lysosomal amino acid sensing machinery that controls mTORC1. Nature (2015) 519(7544):477-81. doi:10.1038/ nature 14107

65. Wang S, Tsun ZY, Wolfson RL, Shen K, Wyant GA, Plovanich ME, et al. Metabolism. Lysosomal amino acid transporter SLC38A9 signals arginine sufficiency to mTORC1. Science (2015) 347(6218):188-94. doi:10.1126/ science. 1257132

66. Pramod AB, Foster J, Carvelli L, Henry LK. SLC6 transporters: structure, function, regulation, disease association and therapeutics. Mol Aspects Med (2013) 34(2-3):197-219. doi:10.1016/j.mam.2012.07.002

67. Seow HF, Broer S, Broer A, Bailey CG, Potter SJ, Cavanaugh JA, et al. Hartnup disorder is caused by mutations in the gene encoding the neutral amino acid transporter SLC6A19. Nat Genet (2004) 36(9):1003-7. doi:10.1038/ng1406

68. Broer S. The SLC38 family of sodium-amino acid co-transporters. Pflugers Arch (2014) 466(1):155-72. doi:10.1007/s00424-013-1393-y

69. Barretina J, Caponigro G, Stransky N, Venkatesan K, Margolin AA, Kim S, et al. The cancer cell line encyclopedia enables predictive modelling of anticancer drug sensitivity. Nature (2012) 483(7391):603-7. doi:10.1038/ nature11003

70. Gaglio D, Metallo CM, Gameiro PA, Hiller K, Danna LS, Balestrieri C, et al. Oncogenic K-Ras decouples glucose and glutamine metabolism to support cancer cell growth. Mol Syst Biol (2011) 7:523. doi:10.1038/msb. 2011.56

71. Vander Heiden MG, Cantley LC, Thompson CB. Understanding the Warburg effect: the metabolic requirements of cell proliferation. Science (2009) 324(5930):1029-33. doi:10.1126/science.1160809

72. Damiani C, Colombo R, Gaglio D, Mastroianni F, Pescini D, Westerhoff HV, et al. A metabolic core model elucidates how enhanced utilization of glucose and glutamine, with enhanced glutamine-dependent lactate production, promotes cancer cell growth: the WarburQ effect. PLoS Comput Biol (2017) 13(9):e1005758. doi:10.1371/journal.pcbi.1005758

73. Metallo CM, Gameiro PA, Bell EL, Mattaini KR, Yang J, Hiller K, et al. Reductive glutamine metabolism by IDH1 mediates lipogenesis under hypoxia. Nature (2011) 481(7381):380-4. doi:10.1038/nature10602

74. Jiang L, Shestov AA, Swain P, Yang C, Parker SJ, Wang QA, et al. Reductive carboxylation supports redox homeostasis during anchorage-independent growth. Nature (2016) 532(7598):255-8. doi:10.1038/nature17393

75. Maddocks OD, Berkers CR, Mason SM, Zheng L, Blyth K, Gottlieb E, et al. Serine starvation induces stress and p53-dependent metabolic remodelling in cancer cells. Nature (2013) 493(7433):542-6. doi:10.1038/ nature 11743
76. Alberghina L, Gaglio D, Gelfi C, Moresco RM, Mauri G, Bertolazzi P, et al. Cancer cell growth and survival as a system-level property sustained by enhanced glycolysis and mitochondrial metabolic remodeling. Front Physiol (2012) 3:362. doi:10.3389/fphys.2012.00362

77. Jiang L, Kon N, Li T, Wang SJ, Su T, Hibshoosh H, et al. Ferroptosis as a p53mediated activity during tumour suppression. Nature (2015) 520(7545): 57-62. doi:10.1038/nature14344

78. Gaglio D, Soldati C, Vanoni M, Alberghina L, Chiaradonna F. Glutamine deprivation induces abortive s-phase rescued by deoxyribonucleotides in k-ras transformed fibroblasts. PLoS One (2009) 4(3):e4715. doi:10.1371/ journal.pone.0004715

79. de la Rosa V, Campos-Sandoval JA, Martin-Rufian M, Cardona C, Mates JM, Segura JA, et al. A novel glutaminase isoform in mammalian tissues. Neurochem Int (2009) 55(1-3):76-84. doi:10.1016/j.neuint.2009.02.021

80. Katt WP, Cerione RA. Glutaminase regulation in cancer cells: a druggable chain of events. Drug Discov Today (2014) 19(4):450-7. doi:10.1016/j.drudis. 2013.10.008

81. Gao P, Tchernyshyov I, Chang TC, Lee YS, Kita K, Ochi T, et al. c-Myc suppression of miR-23a/b enhances mitochondrial glutaminase expression and glutamine metabolism. Nature (2009) 458(7239):762-5. doi:10.1038/ nature 07823

82. Fung MKL, Chan GC. Drug-induced amino acid deprivation as strategy for cancer therapy. J Hematol Oncol (2017) 10(1):144. doi:10.1186/s13045017-0509-9

83. Bak LK, Zieminska E, Waagepetersen HS, Schousboe A, Albrecht J. Metabolism of [U-13C]glutamine and [U-13C]glutamate in isolated rat brain mitochondria suggests functional phosphate-activated glutaminase activity in matrix. Neurochem Res (2008) 33(2):273-8. doi:10.1007/s11064-0079471-1

84. Atlante A, Passarella S, Minervini GM, Quagliariello E. Glutamine transport in normal and acidotic rat kidney mitochondria. Arch Biochem Biophys (1994) 315(2):369-81. doi:10.1006/abbi.1994.1513

85. Indiveri C, Abruzzo G, Stipani I, Palmieri F. Identification and purification of the reconstitutively active glutamine carrier from rat kidney mitochondria. Biochem J (1998) 333(Pt 2):285-90. doi:10.1042/bj3330285

86. Sastrasinh S, Sastrasinh M. Glutamine transport in submitochondrial particles. Am J Physiol (1989) 257(6 Pt 2):F1050-8.

87. Dejure FR, Royla N, Herold S, Kalb J, Walz S, Ade CP, et al. The MYC mRNA 3'-UTR couples RNA polymerase II function to glutamine and ribonucleotide levels. EMBO J (2017) 36(13):1854-68. doi:10.15252/embj.201796662

88. Cheng T, Sudderth J, Yang C, Mullen AR, Jin ES, Mates JM, et al. Pyruvate carboxylase is required for glutamine-independent growth of tumor cells. Proc Natl Acad Sci U S A (2011) 108(21):8674-9. doi:10.1073/pnas.1016627108

89. Katt WP, Lukey MJ, Cerione RA. A tale of two glutaminases: homologous enzymes with distinct roles in tumorigenesis. Future Med Chem (2017) 9(2):223-43. doi:10.4155/fmc-2016-0190

90. Giacomini KM, Huang SM. Transporters in drug development and clinical pharmacology. Clin Pharmacol Ther (2013) 94(1):3-9. doi:10.1038/clpt. 2013.86

91. Colas C, Grewer C, Otte NJ, Gameiro A, Albers T, Singh K, et al. Ligand discovery for the alanine-serine-cysteine transporter (ASCT2, SLC1A5) from homology modeling and virtual screening. PLoS Comput Biol (2015) 11(10):e1004477. doi:10.1371/journal.pcbi.1004477

92. Costa M, Rosell A, Alvarez-Marimon E, Zorzano A, Fotiadis D, Palacin M. Expression of human heteromeric amino acid transporters in the yeast Pichia pastoris. Protein Expr Purif (2013) 87(1):35-40. doi:10.1016/j.pep. 2012.10.003

93. Albers T, Marsiglia W, Thomas T, Gameiro A, Grewer C. Defining substrate and blocker activity of alanine-serine-cysteine transporter 2 (ASCT2) ligands with novel serine analogs. Mol Pharmacol (2012) 81(3):356-65. doi:10.1124/ mol.111.075648

94. Augustyn E, Finke K, Zur AA, Hansen L, Heeren N, Chien HC, et al. LAT-1 activity of meta-substituted phenylalanine and tyrosine analogs. Bioorg Med Chem Lett (2016) 26(11):2616-21. doi:10.1016/j.bmcl.2016.04.023

95. Scalise M, Pochini L, Giangregorio N, Tonazzi A, Indiveri C. Proteoliposomes as tool for assaying membrane transporter functions and interactions with xenobiotics. Pharmaceutics (2013) 5(3):472-97. doi:10.3390/ pharmaceutics5030472 
96. Oppedisano F, Catto M, Koutentis PA, Nicolotti O, Pochini L, Koyioni M, et al. Inactivation of the glutamine/amino acid transporter ASCT2 by 1,2,3-dithiazoles: proteoliposomes as a tool to gain insights in the molecular mechanism of action and of antitumor activity. Toxicol Appl Pharmacol (2012) 265(1):93-102. doi:10.1016/j.taap.2012.09.011

97. Napolitano L, Scalise M, Koyioni M, Koutentis P, Catto M, Eberini I, et al. Potent inhibitors of human LAT1 (SLC7A5) transporter based on dithiazole and dithiazine compounds for development of anticancer drugs. Biochem Pharmacol (2017) 143:39-52. doi:10.1016/j.bcp.2017. 07.006
Conflict of Interest Statement: The authors declare that the research was conducted in the absence of any commercial or financial relationships that could be construed as a potential conflict of interest.

Copyright (C) 2017 Scalise, Pochini, Galluccio, Console and Indiveri. This is an open-access article distributed under the terms of the Creative Commons Attribution License (CC BY). The use, distribution or reproduction in other forums is permitted, provided the original author(s) or licensor are credited and that the original publication in this journal is cited, in accordance with accepted academic practice. No use, distribution or reproduction is permitted which does not comply with these terms. 